\title{
Optimization of extraction of defatted walnut powder by ultrasonic assisted and artificical neural network
}

\author{
Xiajing XU ${ }^{1}$ (D), Shumeng REN ${ }^{1}$, Dongmei WANG ${ }^{2}$, Jing $\mathrm{MA}^{1}$, Xiaowei YAN ${ }^{1}$, Yongli GUO ${ }^{1}$, Xiaoqiu LIU ${ }^{1}$, Yingni PAN ${ }^{1 *}$
}

\begin{abstract}
In order to obtain the extraction process of defatted walnut powder (DWP), an ultrasound-assisted extraction based on artificial neural network was established, and the activity of the extract was evaluated. The artificial neural network (ANN) was used to model different parameters, including the yield of extraction, the concentrations of glansreginin A and ellagic acid, and obtained the optimal extraction process: solvent to material ratio of $9.5 \mathrm{~mL} / \mathrm{g}$, ethanol concentration of $68 \%$, extraction period of $55 \mathrm{~min}$, and extraction three times. Then, the antioxidant scavenging ability of DWP obtained by ANN was compared with other extraction methods. The results showed that DWP extracted by artificial neural network demonstrated good activity in scavenging DPPH and ABTS radicals.
\end{abstract}

Keywords: ultrasound-assisted extraction; defatted walnut powder; artificial neural network; antioxidant activity.

Practical Application: Using artificial neural network as a method for optimizing defatted walnut powder can obtain the best combination of extraction parameters to reduce resource consumption as well as increasing commercial value.

\section{Introduction}

Walnut kernel (WK, a mature seed of Juglans regia L.), recorded in the 2020 edition of the Chinese Pharmacopoeia, is a popular functional food riched in nutrients, which is the good source for commercial production of edible oils due to its high oil and essential fatty acids (Liang et al., 2017). WK is widely accepted by consumers and has established great popularity in the international market with strong demand for its pleasant flavor and health benefits. However, defatted walnut powder (DWP), the residue of walnut kernel removal of walnut oil, is usually discarded as a waste. Because of its bitterness and astringency, the market acceptance of DWP and the relative products is limited in walnut foods (Li et al., 2020b; Liang et al., 2017). The slightly astringent flavor of walnut fruits has been associated with the presence of phenolic compounds (Wu et al., 2014; Liang et al., 2017). Pharmacological studies have shown that the phenolic compounds in DWP exhibited a variety of biological activities among anti-oxidant actions (Bati et al., 2015), lowering blood lipids, and treating hypercholesterolemia (Anderson et al., 2001). Therefore, the development and utilization of DWP are of great significance to improve its potential economic value.

It is reported that DWP has various phenolic components and dicarboxylic acid derivatives (Grace et al., 2014), such as glansreginin A and ellagic acid (Ito et al., 2007). Glansreginin A has the ability to exert neuroprotective effect via anti-inflammation in the brain (Haramiishi et al., 2020). Ellagic acid is a powerful antioxidant and is able to deactivate a wide variety of free radicals in aqueous solution and physiological $\mathrm{pH}$, even when present at low concentrations (Galano et al., 2014). Furthermore, ellagic acid has an anti-inflammatory action, reduces lipid peroxidation and prevents some important diseases such as hypercholesterolemia (Yu et al., 2005). Studies have shown that the content of phenolics in DWP, such as ellagic acid (Hamada et al., 2019), depends on temperature. Hence, it is urgent to establish an effective extraction method to maximize the yield of compounds.

Recently, green technologies, such as ultrasound-assisted extraction (Carrillo-Lopez et al., 2019), have increasingly attracted attention for the extraction of bioactive compounds from plant materials. In order to avoid the negative effects of the conventional thermal processing, ultrasound-assisted statistical analysis method could be adopted for design to obtain the best process parameters ( $\mathrm{Li}$ et al., 2020a). Ultrasound offers an alternative to the traditional methods on extraction procedures to increase the efficiency of production and contributes to the preservation of the environment with a dynamic development in applied research and in the food industry respect (Pinon et al., 2019). When applying the ultrasound, the sound wave goes through the medium causing a series of effects to increase the shelf life, ensure the safety, quality and consumer perception without adversely affecting the nutrients (Vidal et al., 2020; Yikmis, 2020).

Back-propagation (BP), as a type of artificial neural network (ANN), is a nonlinear multivariate modeling computing system that can estimate the response according to the training data within the research scope (Pan et al., 2017; Rajković et al., 2013; Bourquin et al., 1998). Artificial neurons and nodes are arranged in parallel to form a BP neural network, which include the input and output layer containing corresponding nodes for 
each independent and dependent variable, and one or more hidden layers for processing data (Kavuncuoglu et al., 2018; Gonçalves et al., 2005). In recent years, ANN has been applied to optimize a range of natural products extract processes and show a strong correlation with experimental results (Pilkington et al., 2014).

The purpose of this study was to optimize the process parameters of DWP with ultrasound-assisted extraction based on artificial neural network, and further investigated the ability of DWP in the treatment of radical scavenging in DPPH and ABTS.

\section{Materials and methods}

\subsection{Chemicals and reagents}

Glansreginin A and ellagic acid were prepared by our laboratory (purity > 98\%). HPLC-grade acetonitrile, formic acid and 2, 2'-azino-bis(3-ethylbenzothiazoline-6-sulfonic acid) (ABTS) were obtained from Sigma Aldrich (Steinheim, Germany). The ethyl alcohol was supplied by Damao Chemical Reagent Factory (Tianjin, China). The 1,1-Diphenyl-2-picryldydrazyl (DPPH) was provided by Shanghai Macklin Biochemical Company (Shanghai, China).

\subsection{Ultrasound assisted extraction of DWP}

Walnuts kernels were collected in Yunnan Province, China, and identified as the mature seeds of Juglans regia L. by Dr. Yingni Pan, Shenyang Pharmaceutical University. Powder walnut kernels were immersed in a 3-fold volume of petroleum ether $\left(30-60^{\circ} \mathrm{C}\right)$ for $1 \mathrm{~h}$ and sonicated 3 times for $30 \mathrm{~min}$. After being filtered, the residues were collected and dried to obtain DWP.

The crude extraction of defatted walnut kernel was obtained by the ultrasound extraction (Kunshan, KQ5200, 200W). The filtrate was vacuum, concentrated and dried in $60^{\circ} \mathrm{C}$. The obtained material was marked as DWP extract (DWPE).

\subsection{Analysis of main components in DWP by HPLC}

Glansreginin A and ellagic acid in DWPE were determined using an HPLC system (Shimadzu Corporation of Japan) with a diode-array detector. The chromatographic separation was carried out using an Agilent TC- $\mathrm{C}_{18}$ column $(4.6 \times 250 \mathrm{~mm}$, $5 \mu \mathrm{m})$ with a $5 \mathrm{~mm}$ pre-column filter. The mobile phase was a gradient system of acetoni-trile (A) and $0.1 \%$ trifluoroacetic acid (B) at a flow rate of $0.8 \mathrm{~mL} / \mathrm{min}$ and the detector wavelength was $265 \mathrm{~nm}$. The gradient program was as follows: $0-10 \mathrm{~min}$, 10-22\% (A); 10-15 min, 22-23\% (A); 15-20 min, $23-37 \%$ (A); 20-30 min, 37-43\% (A); 30-35 min, 43-60\% (A).

$5 \mathrm{mg} / \mathrm{mL}$ of DWPE, $0.3 \mathrm{mg} / \mathrm{mL}$ of glansreginin A and $0.2 \mathrm{mg} / \mathrm{mL}$ of ellagic acid in methanol were injected into the HPLC system for analysis after filtration with $0.22 \mu \mathrm{m}$ membrane.

\subsection{Modeling and optimization of BP neural network}

Various parameters played an important role in the optimization of the experimental conditions to establish the method of solvent extraction. The orthogonal experiments were designed for four factors and three levels to test solvent to material ratio $(6,8$ and $10 \mathrm{~mL} / \mathrm{g})$, ethanol concentration (50, 60 and $70 \%, v / v)$, extraction period $(20,30$ and $40 \mathrm{~min})$, and extraction frequency (once, twice and three times) as the factors (Pan et al., 2017), and the yield of extraction, the concentrations of glansreginin A and ellagic acid as the index.

In this work, a feed-forward neural network trained with an error back-propagation algorithm was applied to data analysis and model building using MATLAB Neural Network Toolbox (Version 6.5, Mathworks, Natick, MA, USA). The schematic diagram of the specific artificial neural network structure was shown in Figure 1.

Various parameters, such as solvent to material ratio, ethanol concentration, extraction period, and extraction frequency, obtained by orthogonal experiment, were used as the input

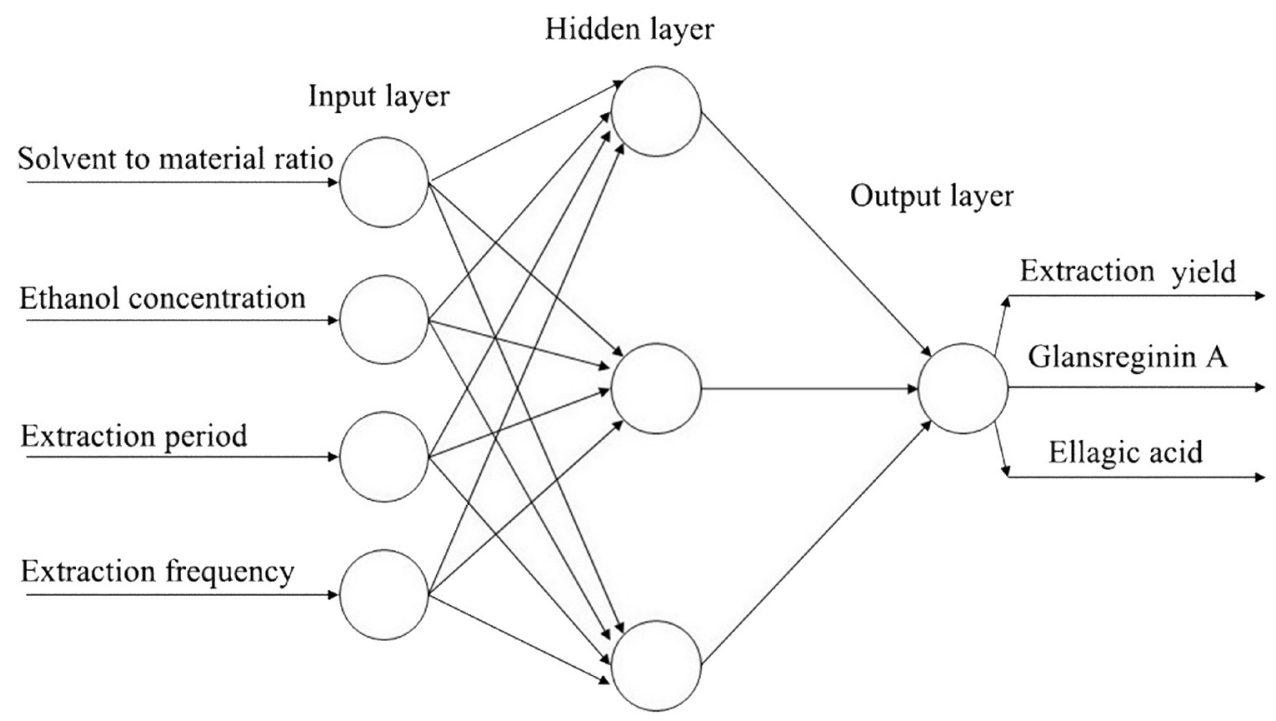

Figure 1. Schematic diagram of artificial neural network structure. 
layer of the BP neural network. The input data, standardized by appropriate functions, were further normalized between 0 and 1 (Khajeh \& Barkhordar, 2013) (Equation 1):

$$
y=\frac{x-x_{\min }}{x_{\max }-x_{\min }}
$$

where $x$ is variable, $x_{\text {max }}$ is maximum value and $x_{\text {min }}$ is minimum value.

The yield of extraction, the concentrations of glansreginin A and ellagic acid were used as the output layer and the number of hidden layers to one level and hidden layer nodes to 2 to 12 layers were set. The optimal numbers of hidden layer nodes were determined by the minimum mean square error and the maximum correlation coefficient, so the BP neural network was established.

Supervised learning was used to train this network. The predicted values and desired values were compared with each other, and the errors were obtained by the difference between the predicted values and experimental values. The weights were adjusted by an error back-propagation algorithm which was used as a gradient descent approach in which weights were changed in proportion to the negative of the error gradient. After reaching a set minimum, the training iterations were stopped (Wen et al., 2012).

The optimized BP neural network was used to simulate the ultrasonic extraction process. The influence of different process parameters on the test results could be obtained according to changing one process parameter. The best results were acquired owing to analyze the simulated data. Then the optimal extraction conditions were verified by weighing $5 \mathrm{~g}$ DWP samples.

\subsection{Assay of DPPH radical scavenging activity}

Selected 10 samples of $2.5 \mathrm{~g}$ each, one of which was extracted through the optimal process of neural network, and the remaining 9 were extracted according to the process of orthogonal experiment, then compared their activity of DPPH. $0.05 \mathrm{mg} / \mathrm{mL}$ aliquot of the diluent of the DWP (10000 times) was added to $100 \mu \mathrm{L}$ of $0.05 \mathrm{mg} / \mathrm{mL}$ DPPH in ethanol. The reaction mixture was incubated in the dark at room temperature for $30 \mathrm{~min}$. The absorbance was measured at $517 \mathrm{~nm}$. The control contained all reagents except the extract sample while ethanol was used as the blank. All measurements were conducted out at least thrice. The scavenging activity of DPPH radicals scavenging was expressed as (Equation 2):

Scavenging rate $(\%)=\left(1-\frac{A S-A C}{A}\right) \times 100 \%$

where $A_{s}$ is the absorbance of the reaction solution, $A_{c}$ is the absorbance of the solution including sample and ethanol, and $\mathrm{A}$ is the absorbance of the solution including DPPH and ethanol.

\subsection{Determination of ABTS radical scavenging activity}

The ABTS radical scavenging activity was measured similarly to that of DPPH, with some modifications. Compare the ability of DWP obtained by different methods to scavenge radicals of ABTS. $7 \mathrm{mmol} / \mathrm{L}$ ABTS solution was added in equal proportion to $2.45 \mathrm{mmol} / \mathrm{L}$ potassium persulfate solution. The reaction mixture was incubated in the dark at room temperature for 14 hours. When the absorbance was measured at $734 \mathrm{~nm}$ wavelength of $0.70 \pm 0.02$ to generate ABTS radical stock solution. $100 \mu \mathrm{L}$ sample solution was mixed with 100ul ABTS solution for 6 minutes, and the absorbance value was measured at $734 \mathrm{~nm}$. All measurements were conducted out at least thrice. The scavenging activity of ABTS radicals scavenging was expressed as (Equation 3):

Scavenging rate $(\%)=\frac{A-A C}{A} \times 100 \%$

where $A_{c}$ is the absorbance of the solution including sample and $\mathrm{ABTS}$, and $\mathrm{A}$ is the absorbance of the solution including ABTS.

\section{Results and discussion}

The analysis showed that glansreginin A and ellagic acid were the main components of DWP through HPLC, which the concentrations were $2.43 \%$ and $1.91 \%$ respectively (Figure 2 ). The results was similar to those reported in Liang et al.(Liang et
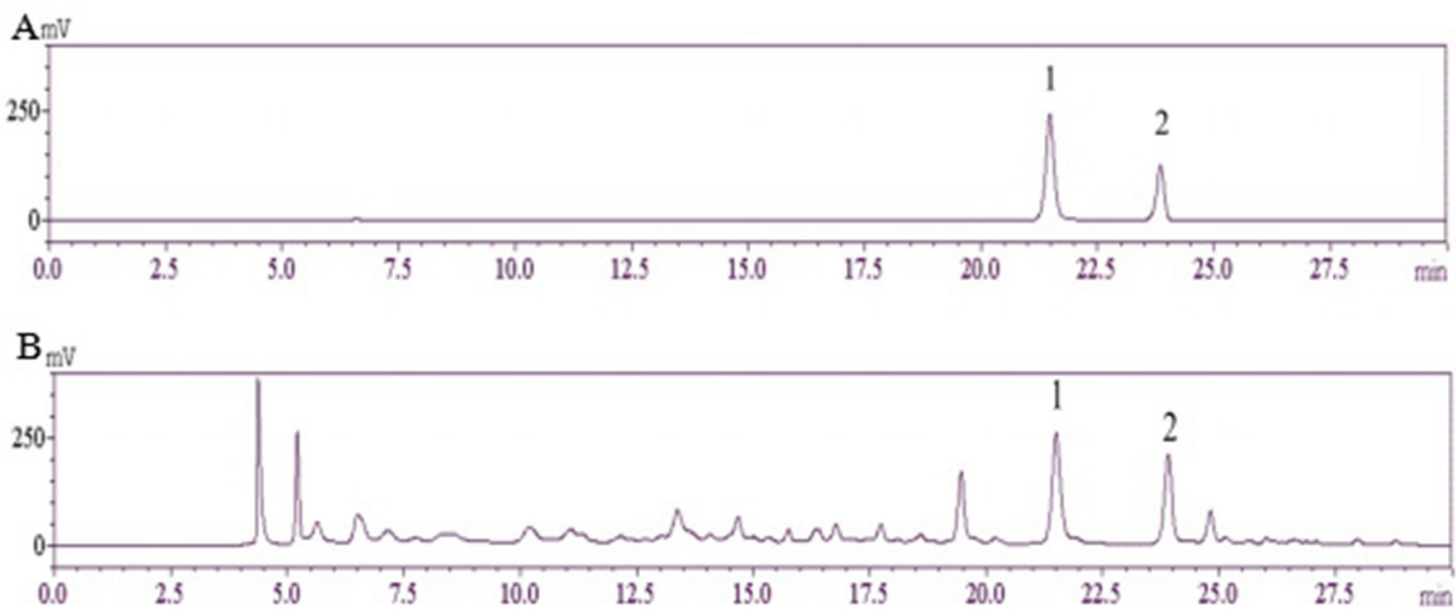

Figure 2. Chromatograms of HPLC of standard compounds (A) and DWPE (B). 
Table 1. Results of orthogonal experiment.

\begin{tabular}{|c|c|c|c|c|c|c|c|}
\hline No. & A & B & $\mathrm{C}$ & $\mathrm{D}$ & $\begin{array}{l}\text { Extraction yield } \\
(\mathrm{g})\end{array}$ & $\begin{array}{c}\text { Glansreginin A } \\
(\mathrm{mg})\end{array}$ & Ellagic acid (mg) \\
\hline 1 & 6 & 50 & 20 & 1 & 0.210 & 47.87 & 33.29 \\
\hline 2 & 6 & 60 & 30 & 2 & 0.564 & 108.61 & 97.83 \\
\hline 3 & 6 & 70 & 40 & 3 & 0.688 & 130.57 & 170.93 \\
\hline 4 & 8 & 50 & 30 & 3 & 0.780 & 176.35 & 171.80 \\
\hline 5 & 8 & 60 & 40 & 1 & 0.476 & 99.63 & 105.26 \\
\hline 6 & 8 & 70 & 20 & 2 & 0.593 & 122.57 & 139.65 \\
\hline 7 & 10 & 50 & 40 & 2 & 0.729 & 162.30 & 197.88 \\
\hline 8 & 10 & 60 & 20 & 3 & 0.768 & 196.51 & 226.17 \\
\hline 9 & 10 & 70 & 30 & 1 & 0.486 & 95.77 & 153.50 \\
\hline $\mathrm{k} 1$ & 0.487 & 0.573 & 0.524 & 0.391 & & & \\
\hline $\mathrm{k} 2$ & 0.616 & 0.603 & 0.610 & 0.629 & & & \\
\hline $\mathrm{k} 3$ & 0.661 & 0.589 & 0.631 & 0.745 & & & \\
\hline $\mathrm{R}$ & 0.174 & 0.030 & 0.107 & 0.354 & & & \\
\hline $\mathrm{k}_{1}^{\prime}$ & 95.683 & 128.840 & 122.317 & 81.090 & & & \\
\hline $\mathrm{k}_{2}^{\prime}$ & 132.850 & 134.917 & 126.910 & 131.160 & & & \\
\hline $\mathrm{k}_{3}^{\prime}$ & 151.527 & 116.303 & 130.833 & 167.810 & & & \\
\hline $\mathrm{R}^{\prime}$ & 55.844 & 18.614 & 8.516 & 86.720 & & & \\
\hline $\mathrm{k}_{1}$ & 100.683 & 134.323 & 133.037 & 97.350 & & & \\
\hline $\mathrm{k}_{2}$ & 138.903 & 143.087 & 141.043 & 145.120 & & & \\
\hline $\mathrm{k}_{3}$ & 192.517 & 154.693 & 158.023 & 189.633 & & & \\
\hline R" & 91.834 & 20.370 & 24.986 & 92.283 & & & \\
\hline
\end{tabular}

al., 2017). The traditional extraction method had an influence on the polyphenols contents in DWP, which may be related to the decomposition of phenolics at high temperature (Wen et al., 2012). Therefore, the experiment chose ultrasonic technology as the extraction process, which characterized short time, low temperature and high efficiency (Wen et al., 2012).

The intuitionistic analysis showed that 4 factors, including solvent to material ratio, ethanol concentration, extraction period, and extraction frequency, had great influence on the experimental results (Table 1). Among them, extraction frequency and solvent to material ratio was the most important parameter. However, the estimate of error cannot be calculated by intuitionistic analysis, which cannot accurately reflect the experimental error or a substantial change between the levels. Therefore, in order to fully and more accurately express the experimental results, further analysis is needed.

In the present work, the trained BP neural network showed very good results for the training subset of data. When four hidden layer numbers, nine iterations times were used for the network (Figure 3A, B), the accuracy between the predicted value and the experimental value was higher. Good correlation has been obtained as it is proved by the correlation coefficient of $\mathrm{R}=1$. The yield of extraction, the concentrations of glansreginin A and ellagic acid as predicted by the BP neural network were compared with the experimentally obtained values. It was found that the predicted values were similar to the true values (Table 2).

The already developed ANN model has been further used for the investigation of the way in which solvent to material ratio, ethanol concentration, extraction period, and extraction frequency influence on the yield of extraction, the concentrations of glansreginin A and ellagic acid. With the increase of liquidsolid ratio, the yield of extraction increased firstly and then decreased with one maximum value. The concentrations of glansreginin A and ellagic acid showed that the same monotone increasing trend and tended to be gentle. With the increase of extraction time, the extraction yield reached its maximum value when the extraction time was at $55 \mathrm{~min}$ and the variation trend of concentrations of glansreginin A and ellagic acid were slight. With the increase of ethanol concentration, the maximum yield of extraction appeared when the ethanol concentration was $68 \%$ and the concentrations of glansreginin A and ellagic acid showed opposite trend (Figure 3C-H). Considering that properties of integers, actual production cost and other factors, extraction frequency was determined to be 3 times.

Combined with the changing trend of the simulated process diagram, the optimal process parameters of the simulated ultrasonic extraction of DWP were obtained as follows: solvent to material ratio of $9.5 \mathrm{~mL} / \mathrm{g}$, ethanol concentration of $68 \%$, extraction period of $55 \mathrm{~min}$, and extraction three times. The results obtained by BP neural network simulation under the optimal parameters were: extraction yield $0.841 \mathrm{~g}$, glansreginin A $231.92 \mathrm{mg}$ and ellagic acid $206.57 \mathrm{mg}$. In the verification experiment, the results showed that the yield of extraction was $0.823 \mathrm{~g}$, the concentrations of glansreginin A and ellagic acid were $227.52 \mathrm{mg}$ and $203.24 \mathrm{mg}$ respectively, and significant difference could not found between the predicted and experimental value.

The DPPH and ABTS methods were the common systems to evaluate the antioxidant activity of natural antioxidants. The clearance rates of DPPH and ABTS were positively correlated with the antioxidant capacity of the drug (Wen et al., 2012). DWP was provided by orthogonal experiment nine extractions 
A

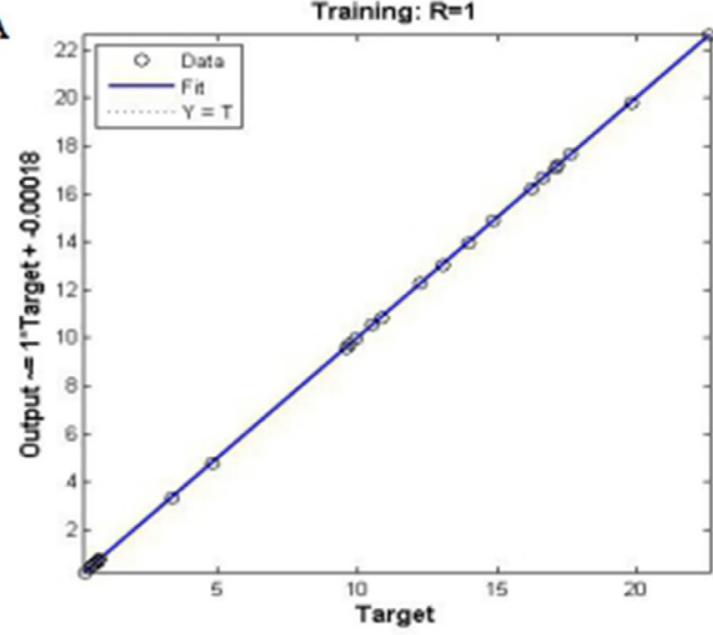

B

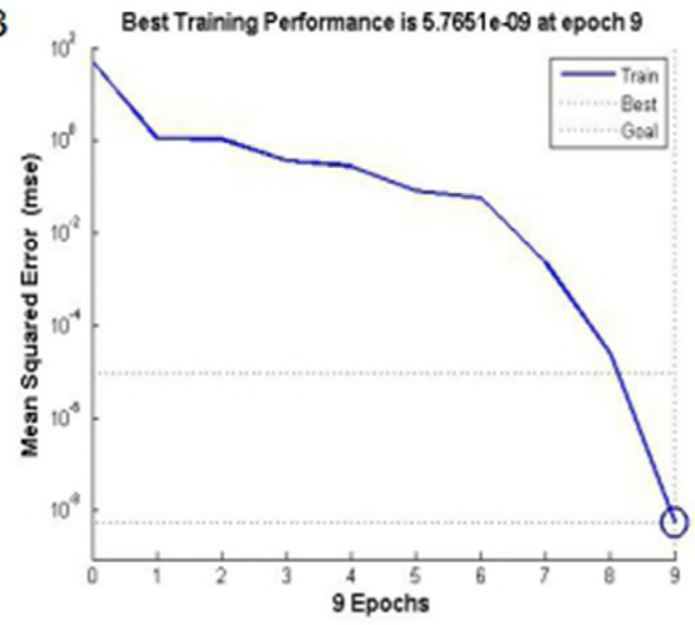

E
$\mathrm{C}$

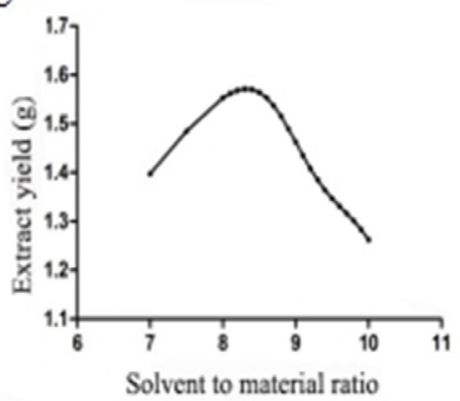

F

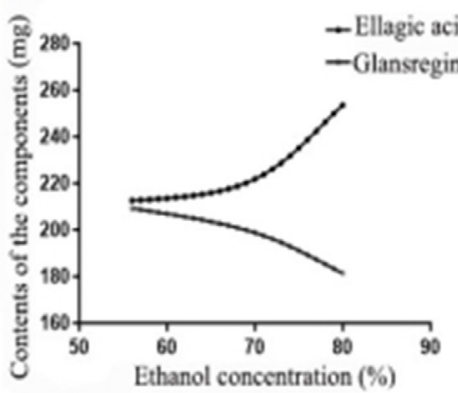

D

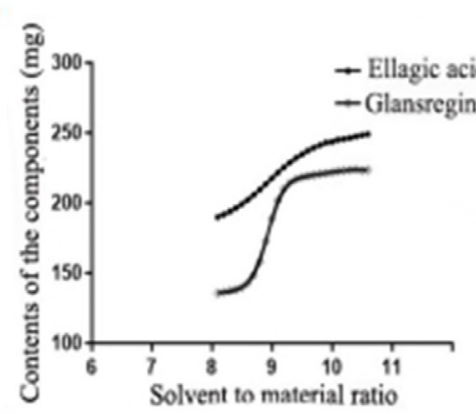

$\mathrm{G}$

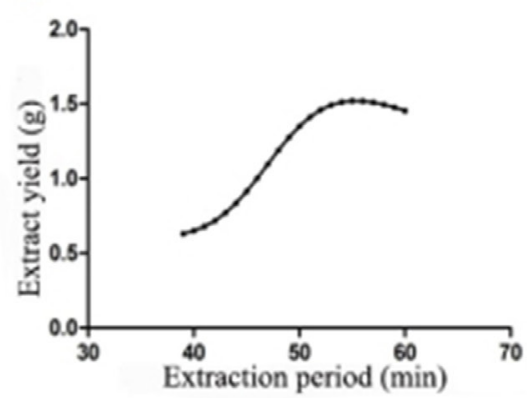

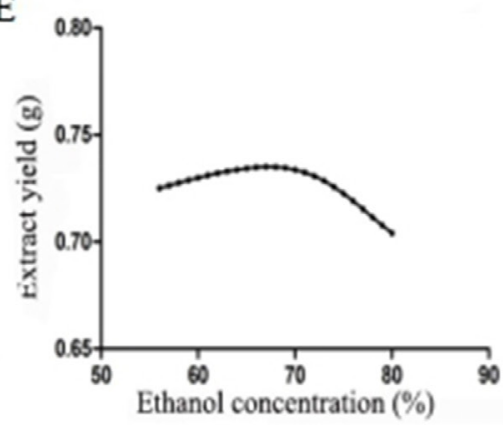

$\mathrm{H}$

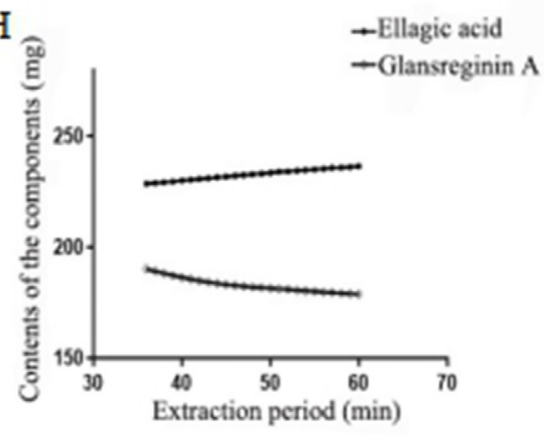

Figure 3. BP neural network simulation extraction process. (A-B) Regression coefficient and iterative convergence diagrams of BP neural network. (C-D) The effect of simulated liquid-solid ratio on ultrasonic extraction technology. (E-F) The effect of simulated ethanol concentration on ultrasonic extraction technology. (G-H) The effect of simulated extraction time on ultrasonic extraction technology.

Table 2. The predicted values of the neural network and the experimental values for the extraction yield, the concentrations of ellagic acid and glansreginin A.

\begin{tabular}{|c|c|c|c|c|c|c|}
\hline \multirow{2}{*}{ No. } & \multicolumn{2}{|c|}{ Extraction yield (g) } & \multicolumn{2}{|c|}{ Glansreginin A (mg) } & \multicolumn{2}{|c|}{ Ellagic acid (mg) } \\
\hline & Experimental value & predict value & Experimental value & predict value & Experimental value & predict value \\
\hline 1 & 0.210 & 0.2104 & 47.87 & 47.88 & 33.29 & 33.29 \\
\hline 2 & 0.564 & 0.5639 & 108.61 & 108.61 & 97.83 & 97.38 \\
\hline 3 & 0.688 & 0.6881 & 130.57 & 130.58 & 170.93 & 170.93 \\
\hline 4 & 0.780 & 0.7801 & 176.35 & 176.35 & 171.80 & 171.80 \\
\hline 5 & 0.476 & 0.4759 & 99.63 & 99.63 & 105.26 & 105.26 \\
\hline 6 & 0.593 & 0.5929 & 122.57 & 122.57 & 139.65 & 139.65 \\
\hline 7 & 0.729 & 0.729 & 162.30 & 162.30 & 197.88 & 197.88 \\
\hline 8 & 0.768 & 0.7679 & 196.51 & 196.51 & 226.17 & 226.17 \\
\hline 9 & 0.486 & 0.4863 & 95.77 & 95.78 & 153.50 & 148.64 \\
\hline
\end{tabular}




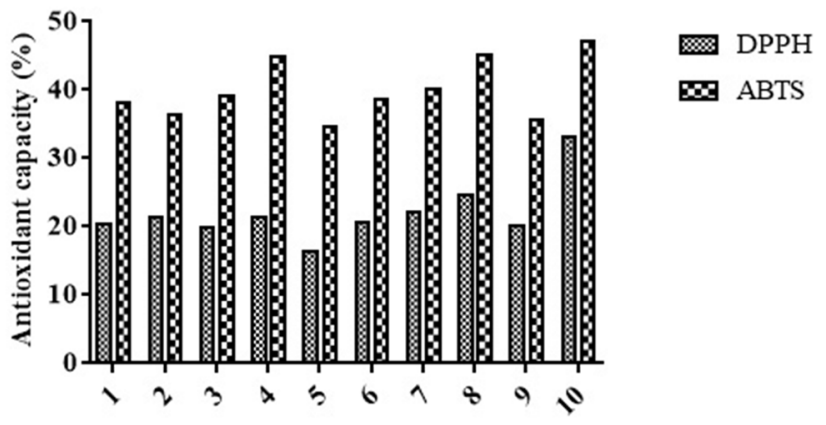

Figure 4. Antioxidant ability of DPW obtained by different extraction methods. DWP provided by different extractions methods (group 1-10). Group 1-9 supplied by orthogonal experiment nine extractions.

(group 1-9), and another was supplied by the extraction process of artificial neural network. In accordance with evaluation the antioxidant capacity of DWP obtained by different extraction methods, it was found that DWP extracted by the artificial neural network (group 10) had the highest clearance rates for DPPH and ABTS compared other extraction methods, which were $33.22 \%$ and $47.02 \%$, respectively. This result, which DWP was provided by the artificial neural network had the highest clearance rates for DPPH and ABTS compared other extraction methods, further illustrated the advantages of artificial neural network in the extraction process of traditional Chinese medicine, which could provide more accurate parameters and the reference for other medicine extractions (Figure 4).

\section{Conclusion}

Optimization of the model using the artificial neural network method showed that setting solvent to material ratio of $9.5 \mathrm{~mL} / \mathrm{g}$, ethanol concentration of $68 \%$, extraction period of $55 \mathrm{~min}$, and extraction three times could obtain the extract with good activity in scavenging DPPH and ABTS radicals. The results of this study showed optimizing the process of extraction can increase the possibility of saving resources.

\section{Acknowledgement}

This study was supported by National Science Foundation of China (No. 41310949) and the Fourth Investigation of Traditional Chinese Medicine resources in Liaoning Province of China (2018014, 2018017, 2019017, 2019019).

\section{References}

Anderson, K. J., Teuber, S. S., Gobeille, A., Cremin, P., Waterhouse, A. L., \& Steinberg, F. M. (2001). Walnut polyphenolics inhibit in vitro human plasma and LDL oxidation. The Journal of Nutrition, 131(11), 2837-2842. http://dx.doi.org/10.1093/jn/131.11.2837. PMid:11694605.

Bati, B., Celik, I., \& Dogan, A. (2015). Determination of hepatoprotective and antioxidant role of walnuts against ethanol-induced oxidative stress in rats. Cell Biochemistry and Biophysics, 71(2), 1191-1198. http://dx.doi.org/10.1007/s12013-014-0328-3. PMid:25391888.

Bourquin, J., Schmidli, H., Van Hoogevest, P., \& Leuenberger, H. (1998). Advantages of Artificial Neural Networks (ANNs) as alternative modelling technique for data sets showing non-linear relationships using data from a galenical study on a solid dosage form. European Journal of Pharmaceutical Sciences, 7(1), 5-16. http://dx.doi.org/10.1016/S0928-0987(97)10028-8. PMid:9845773.

Carrillo-Lopez, L. M., Luna-rodriguez, L., Alarcon-rojo, A. D., \& Huerta-jimenez, M. (2019). High intensity ultrasound homogenizes and improves quality of beef longissimus dorsi. Food Science and Technology, 39(1, Suppl 1), 332-340. http://dx.doi.org/10.1590/ fst.05218.

Galano, A., Francisco Marquez, M., \& Pérez-González, A. (2014). Ellagic acid: an unusually versatile protector against oxidative stress. Chemical Research in Toxicology, 27(5), 904-918. http://dx.doi. org/10.1021/tx500065y. PMid:24697747.

Gonçalves, E. C., Minim, L. A., Coimbra, J. S. R., \& Minim, V. P. R. (2005). Modeling sterilization process of canned foods using artificial neural networks. Chemical Engineering and Processing, 44(12), 12691276. http://dx.doi.org/10.1016/j.cep.2005.04.001.

Grace, M. H., Warlick, C. W., Neff, S. A., \& Lila, M. A. (2014). Efficient preparative isolation and identification of walnut bioactive components using high-speed counter-current chromatography and LC-ESI-ITTOF-MS. Food Chemistry, 158, 229-238. http://dx.doi.org/10.1016/j. foodchem.2014.02.117. PMid:24731336.

Hamada, Y., Haramiishi, R., Ojima, Y., Amakura, Y., Yoshimura, M., Sawamoto, A., Okuyama, S., Furukawa, Y., \& Nakajima, M. (2019). Hydrolysable tannins, gallic acid, and ellagic acid in walnut reduced 3-(4,5-Dimethylthiazol-2-yl)-2,5-Diphenyltetrazolium bromide (MTT) reduction in T-Cells cultured from the spleen of mice. PharmaNutrition, 7, 100140. http://dx.doi.org/10.1016/j. phanu.2018.100140.

Haramiishi, R., Okuyama, S., Yoshimura, M., Nakajima, M., Furukawa, Y., Ito, H., \& Amakura, Y. (2020). Identification of the characteristic components in walnut and anti-inflammatory effect of glansreginin A as an indicator for quality evaluation. Bioscience, Biotechnology, and Biochemistry, 84(1), 187-197. http://dx.doi.org/10.1080/09168 451.2019.1670046. PMid:31566092.

Ito, H., Okuda, T., Fukuda, T., Hatano, T., \& Yoshida, T. (2007). Two novel dicarboxylic acid derivatives and a new dimeric hydrolyzable tannin from walnuts. Journal of Agricultural and Food Chemistry, 55(3), 672-679. http://dx.doi.org/10.1021/jf062872b. PMid:17263459.

Kavuncuoglu, H., Kavuncuoglu, E., Karatas, S. M., Benli, B., Sagdic, O., \& Yalcin, H. (2018). Prediction of the antimicrobial activity of walnut (Juglans regia L.) kernel aqueous extracts using artificial neural network and multiple linear regression. Journal of Microbiological Methods, 148, 78-86. http://dx.doi.org/10.1016/j.mimet.2018.04.003. PMid:29649523.

Khajeh, M., \& Barkhordar, A. (2013). Modelling of solid-phase tea waste extraction for the removal of manganese from food samples by using artificial neural network approach. Food Chemistry, 141(2), 712-717. http://dx.doi.org/10.1016/j.foodchem.2013.04.075. PMid:23790838.

Li, H. Z., Zhang, H. J., Zhang, Z. J., \& Cui, L. X. (2020a). Optimization of ultrasound-assisted enzymatic extraction and in vitro antioxidant activities of polysaccharides extracted from the leaves of Perilla frutescens. Food Science and Technology, 40(1), 36-45. http://dx.doi. org/10.1590/fst.29518.

Li, Y., Chen, D., Zhang, F., Lin, Y., Ma, Y., Zhao, S., Chen, C., Wang, X., \& Liu, J. (2020b). Preventive effect of pressed degreased walnut meal extracts on T2DM rats by regulating glucolipid metabolism and modulating gut bacteria flora. Journal of Functional Foods, 64, 1-13. http://dx.doi.org/10.1016/j.jff.2019.103694.

Liang, X., Chen, D., Cao, L., \& Zhao, S. (2017). Effects of pressed degreased walnut meal extracts on lipid metabolism in postnatally monosodium glutamate-induced mice and 3T3-L1 preadipocytes. 
Journal of Functional Foods, 31, 89-96. http://dx.doi.org/10.1016/j. jff.2017.01.026.

Pan, H., Zhang, Q., Cui, K., Chen, G., Liu, X., \& Wang, L. (2017). Optimization of extraction of linarin from flos chrysanthemi indici by response surface methodology and artificial neural network. Journal of Separation Science, 40(9), 2062-2070. http://dx.doi.org/10.1002/ jssc.201601259. PMid:28319649.

Pilkington, J. L., Preston, C., \& Gomes, R. L. (2014). Comparison of response surface methodology (RSM) and artificialneural networks (ANN) towards efficient extraction of artemisininfrom Artemisia annua. Industrial Crops and Products, 58, 15-24. http://dx.doi. org/10.1016/j.indcrop.2014.03.016.

Pinon, M., Alarcon-rojo, A., Paniwnyk, L., Mason, T., Luna, L., \& Renteria, A. (2019). Ultrasound for improving the preservation of chicken meat. Food Science and Technology, 39(1, Suppl 1), 129-135. http://dx.doi.org/10.1590/fst.39017.

Rajković, K. M., Avramović, J. M., Milić, P. S., Stamenković, O. S., \& Veljković, V. B. (2013). Optimization of ultrasound-assisted basecatalyzed methanolysis of sunflower oil using response surface and artifical neural network methodologies. Chemical Engineering Journal, 215, 82-89. http://dx.doi.org/10.1016/j.cej.2012.10.069.

Vidal, A. R., Cansian, R. L., Mello, D. O., Kubota, E. H., Demiate, I. M., Zielinski, A. A. F., \& Dornelles, R. C. P. (2020). Effect of ultrasound on the functional and structural properties of hydrolysates of different bovine collagens. Food Science and Technology, 40(2), 346-353. http:// dx.doi.org/10.1590/fst.00319.

Wen, L. R., Yang, B., Cui, C., You, L. J., \& Zhao, M. M. (2012). Ultrasoundassisted extraction of phenolics from longan (Dimocarpus longan Lour): fruit seed with artificial neural network and their antioxidant activity. Food Analytical Methods, 5(6), 1244-1251. http://dx.doi. org/10.1007/s12161-012-9370-1.

Wu, W., Zhao, S., Chen, C., Ge, F., Liu, D., \& He, X. (2014). Optimization of production conditions for antioxidant peptides from walnut protein meal using solid-state fermentation. Food Science and Biotechnology, 23(6), 1941-1949. http://dx.doi.org/10.1007/s10068-014-0265-3.

Yikmis, S. (2020). Effect of ultrasound on different quality parameters of functional sirkencubin syrup. Food Science and Technology, 40(1), 258-265. http://dx.doi.org/10.1590/fst.40218.

Yu, M. Y., Chang, W. C., Wu, C. H., \& Chiang, S. Y. (2005). Reduction of oxidative stress and apoptosis in hyperlipidemic rabbits by ellagic acid. The Journal of Nutritional Biochemistry, 16(11), 675-681. http://dx.doi.org/10.1016/j.jnutbio.2005.03.013. PMid:16081267. 